\title{
CONCLUSIONES DEL FORO
}

\section{JORGE CANALES Subdirector de INAFOR}

Lo importante de este foro, de carácter nacional e internacional, fue que los "chapiollos" nicaragüenses lo organizamos. Creo que esto es el valor agregado de este asunto, porque la costumbre es que desde el extranjero nos vengan a organizar este tipo de foros. También quiero agradecer a otros organismos hermanos como el CATIE, FAO. Así mismo, la participación del sector industrial, privado, representado por MAPIINICSA, con quienes esperamos seguir trabajando.

No nos podemos ir sin tener conclusiones de este evento y de los próximos pasos. Creo que el resultado de este esfuerzo marca ya el alto, pero no para quedarnos sin acción. En este encuentro desarrollamos diversas temáticas, encontramos sugerencias, recomendaciones, y nos parece que no pueden quedar en el actor Gobierno, el papa Gobierno, la responsabilidad de la implementación de estas sugerencias en las cuales todos hemos contribuido. Porque el Gobierno es un actor; y esto no es posible sin la voluntad de los pueblos indígenas, de la gente

Quisiera hacer una reflexión alrededor de una primera conclusión. Y es el tema sobre el cual nos montamos recién el huracán. Si ustedes recuerdan fue todo un movimiento masivo y estábamos prácticamente desorientados, porque Puerto Cabezas jamás había vivido ese tipo de fenómenos. En esa oportunidad se reconoce la rápida movilización; y es increíble cómo esa afectación nos dio la oportunidad de observar la rápida movilización, el talento humano que tenemos en la Costa Caribe, el talento humano que tenemos en la RAAN, el talento humano que tenemos en los diferentes municipios afectados por el huracán -y estamos hablando principalmente de aquellos municipios que están articulados con esas cuencas afectadas, como son Rosita, Puerto Cabezas, Waspam, Bonanza y Prinzapolka. Recordamos ahora cómo se volcó ese talento humano integrado en diferentes instancias. Y fuimos conformando, en algún momento, equipos de trabajo que arrojaron análisis de ambiente, análisis sobre daños alrededor de los ecosistemas y, sobre todo, se desarrolló un instrumento que en algún momento, los compañeros que estaban en este esfuerzo dijeron: No podemos seguir dando bandazos; aquí nos están entrando la FAO, OPS, OMS, el Diablo, todo el mundo. Y es aquí cuando se reconoce el liderazgo del Consejo Regional y del Gobierno Regional.

Y este instrumento fue lo que reconocimos como la estrategia o el programa de restauración de nuestros ecosistemas afectado por el huracán Félix en la RAAN. Si ustedes recuerdan, ese instrumento marcó prácticamente seis componentes: el primero fue el fortalecimiento de la institucionalidad, del diálogo, la gobernanza y la organización comunal; el segundo tema fue la protección de estas áreas en cuanto a la protección forestal; el tercero tuvo y tiene una importancia relevante alrededor del ingreso económico, pues se trataba del aprovechamiento y saneamiento, por parte de la forestería comunitaria, de estas áreas afectadas; el cuarto componente fue trabajar alrededor del ordenamiento de estas áreas de alta afectación, con un enfoque de zonificación productiva, potenciando las oportunidades que podía presentar el evento catastrófico; el quinto elemento es el de la investigación, monitoreo y evaluación, el cual está en pañales, pero que ahora, con este foro está marcando un hito interesante, y el sexto tema es el de la reforestación, que se marcaba como uno de los componentes de este programa, en el marco de la estrategia forestal de la RAAN, vinculado a una estrategia que contaba con la participación de las comunidades, es decir, no esperar que hubiese una gran cantidad de plata para ejecutar este componente, sino contar con las potencialidades comunitarias de la zona afectada, y de esta forma generar análisis y ubicar modelos manejables por los actores principales, las comunidades.

Compañeros: Nosotros consideramos, y se lo expresábamos al Cro director de INAFOR, que efectivamente ésta es la oportunidad para hacer los ajustes necesarios al proceso; pero llevando un orden lógico y una coherencia en los temas que se han planteado. Porque hay que organizarse y hay que hacer la reingeniería de este proceso. Y en ese sentido queremos externar la voluntad expresa, al menos del Gobierno de Reconciliación y Unidad Nacional a través de las instituciones líderes -en este caso el INAFOR, y esperamos también que el MARENApara revisar todo lo que sea posible y concertar con las instituciones que sean necesarias. 
Nosotros encontramos, por ejemplo, una demanda alrededor de ver qué es lo que va a pasar con estas áreas afectadas. Efectivamente, carecemos de información que debe estar en caliente, de último momento. Y eso no puede ser posible sin una labor de investigación, de análisis y monitoreo más exhaustivo. Hay una tendencia vinculada al tema de tramitología. Nosotros, como institución especializada tenemos un asterisco alrededor del proceso de aprovechamiento de estas áreas. Una vez caminando la cosa en términos de potencialidad productiva, consideramos que es básico continuar con ese ejercicio. Si es necesario poner más énfasis en el proceso de tramitología, también se puede hacer, pero creemos que la tendencia tiene que marcar la restauración futura de estas áreas potenciales para ser manejadas como bosques.

Lo otro que estamos marcando es que nos incorporamos con líneas de inversión, y aquí lo vamos a hacer público: nos vamos a comprometer públicamente a abrir con mayor fortaleza las actividades en torno al ordenamiento territorial forestal en la RAAN, con un acápite que haga énfasis en estas áreas afectadas por el huracán. En estos días suscribimos un convenio de un millón de córdobas con URACCAN, para intensificar este proceso.

Lo otro está vinculado al tema de establecer, o más bien, operativizar una plataforma sobre el tema de investigación, monitoreo y evaluación, para que tengamos de inmediato una referencia de líderes que nos estén generando información de calidad para tomar decisiones coherentes en este proceso. En ese sentido, nosotros, el Gobierno, el INAFOR, en consulta con las autoridades autónomas, nos apuntamos que el liderazgo descanse en las expresiones regionales. No hacemos esto por localismo, sino por una cuestión de criterios vinculados al área de afectación. Así de sencillo. ¿Por qué URACCAN? ¿Por qué BICU? Sencillamente, porque hay expresión de la región y están a escasos kilómetros de las áreas afectadas. $\mathrm{Y}$ en términos de administración, si lo queremos ver así, también hay reducción de costos de transacción. Los líderes, en nuestra opinión, deben descansar en las expresiones regionales, máxime cuando ya hay alianzas con experiencias acumuladas, como por ejemplo, la incorporación del CIDCA con BICU, y URACCAN con sus institutos.

Es decir, hay un bagaje: y estamos por arrancar también la inversión del Nodo Regional Ambiental en las instalaciones del Gobierno Regional. Creo que esto es interesante y alrededor de eso incorporar a otros actores en alianzas relevantes. Pero quien marca las recomendaciones hacia las instancias que están tomando decisiones, en términos concretos y en términos de legitimidad, son las instituciones que generan conocimientos en las regiones autónomas, porque, precisamente, son parte del patrimonio de la autonomía en ese sentido. $\mathrm{Y}$ en este aspecto marcamos también un compromiso de incorporar inversión pública, al menos desde el INAFOR, porque consideramos que podemos perfectamente halar inversión y con un contrato delegado se pueden ubicar acciones concretas. Pero eso tiene que estar liderado por un equipo; y en ese sentido llamamos al liderazgo del gobierno y el consejo autónomos; y en este contexto sugerimos armar un equipo ad hoc que nos permita estar alimentando la reingeniería de este proceso y, en términos no lejanos, en menos de un mes o de setenta días, tener una propuesta reformulada, con acciones concretas y enfocarnos en lo que se está haciendo, en qué se está invirtiendo y si lo estamos haciendo de madera adecuada o, en otro caso, reorientar esas líneas de inversión.

Les cuento esto, porque si no entramos a esa tarea a lo inmediato vamos a perder el precioso tiempo; y el tema de gestión de recursos no está a la vuelta de la esquina y, en ese sentido, tenemos que hacer una labor seria para poder generar las inversiones. $\mathrm{Al}$ menos, nosotros tenemos la expectativa que si se desarrolla el tema de investigación, monitoreo y evaluación, articulado con las universidades, debe existir en su programa de gestión, al menos por etapa, una referencia de 1.5 a 2 millones de dólares, pues se trata de acciones concretas, porque para poder investigar tenés que incentivar. Nosotros partimos de que el talento humano lo tenemos, y lo que nos resta es -y aquí voy a repetir las palabras del Cro. William Wattler- fortalecer y desarrollar y bajar esa asimetría en el tema tecnológico. Porque si hacemos un mapeo de nuestras capacidades en recursos humanos, estoy seguro que encontraremos que muchos aquí tienen maestrías, posgrados o alguna especialidad. Y si juntamos esas capacidades con el bagaje y experiencia de los comunitarios, quienes realmente podemos decir que son los doctores en ciencias agroforestales, creo que vamos a obtener un buen producto.

Y así sucesivamente. Creo que el Norte está reforzado; hagamos el esfuerzo por articularlo con un buen equipo y marquemos la diferencia en esta segunda etapa del manejo del bosque posthuracán. Creemos que esto no termina en término de emergencia, hasta que el presidente de la república diga: Se suspende el decreto de estado de emergencia en la Región Autónoma del Atlántico Norte. Creo que el decreto tiene una vigencia de unos cinco años o más -hasta hace poco expiró el del huracán Joan.

Bueno, está esa oportunidad, y la verdad es que nosotros no quisiéramos irnos de acá sin conocer la disposición de continuar con este proceso y que sea una referencia de fortalecer la gobernanza en la Región Autónoma del Atlántico Norte. 